\title{
Correlationship between Diabetes Mellitus and Chronic Carbon Monoxide Intoxication
}

\author{
Eni-yimini Solomon Agoro ${ }^{1 *}$, Anthony E. Soroh ${ }^{2,3}$, Caroline Chinenyenwa Thomas ${ }^{3}$ \\ ${ }^{1}$ Department of Biochemistry, Federal University Otuoke, Otuoke, Nigeria \\ ${ }^{2}$ Isaac Jasper Boro College of Education (IJBCOE), Sagbama, Nigeria \\ ${ }^{3}$ Department of Chemical Pathology, Federal Medical Centre, Yenagoa, Nigeria \\ Email: ^enisagoro@gmail.com
}

How to cite this paper: Agoro, E.S., Soroh, A.E. and Thomas, C.C. (2022) Correlationship between Diabetes Mellitus and Chronic Carbon Monoxide Intoxication. Journal of Diabetes Mellitus, 12, 63-74. https://doi.org/10.4236/jdm.2022.121007

Received: April 25, 2021

Accepted: February 5, 2022

Published: February 8, 2022

Copyright ( 2022 by author(s) and Scientific Research Publishing Inc. This work is licensed under the Creative Commons Attribution International License (CC BY 4.0).

http://creativecommons.org/licenses/by/4.0/ (c) (i) Open Access

\begin{abstract}
There is a data gap in the relationship between chronic carbon monoxide intoxication and diabetes mellitus manifestation. This study aims to investigate if a cause-effect relationship exists using rabbits as a choice animal model. A total of twenty rabbits were used for the study comprising equal age and weight-matched control and experimental groups. The experimental group was further divided into 10th day, 20th day and 30th CO intoxicated sub-groups. Vitreous and serum glucose, proteins, lipids, electrolytes and renal function parameters were measured using WHO-approved methods. One-way ANOVA (Post hoc-LSD) and Pearson correlational analysis were used for the data analysis. The result showed a progressive significant increase $(p<0.05)$ in concentrations of vitreous glucose, urea and creatinine in the experimental groups, while the concentrations of vitreous total cholesterol, triglyceride, total protein, globulins, sodium, potassium and $\mathrm{pH}$ decreased significantly. In the same vein, the concentrations of serum glucose, triglyceride, and sodium increased significantly $(\mathrm{p}<0.05)$, whereas concentrations of serum cholesterol, total proteins, globulins, potassium, and $\mathrm{pH}$ activity decreased significantly. Correlational relationships were also observed between glucose and some associated parameters in the vitreous humour and serum. In conclusion, some of the vitreous and serum biochemical parameters altered followed a similar predictive pattern and usual pathophysiology of diabetes mellitus. Therefore, we found that chronic $\mathrm{CO}$ intoxication could be included amongst the environmental agents known to be a causative agent of diabetes mellitus.
\end{abstract}

\section{Keywords}

Diabetes, Carbon Monoxide, Glucose, Proteins, Lipids, Electrolytes 


\section{Introduction}

Diabetes mellitus (DM) is a group of metabolic disorders characterized by a high blood glucose concentration over a prolonged period of time [1]. Diabetes is due to either the pancreas not producing enough insulin, or the cells of the body not responding properly to the insulin produced [2]. There are three main types of diabetes mellitus: type 1, type 2 and gestational. Symptoms often include frequent urination, increased thirst, and increased appetite [3]. Diabetes mellitus is characterized by recurrent or persistent high blood glucose, and is diagnosed by demonstrating fasting plasma glucose concentration $\geq 7.0 \mathrm{mmol} / \mathrm{L}(126 \mathrm{mg} / \mathrm{dL})$ and glycated hemoglobin $\left(\mathrm{HbA}_{1 \mathrm{C}}\right) \geq 48 \mathrm{mmol} / \mathrm{mol}$ ( $\geq 6.5$ DCCT \%) [4] [5].

The International Diabetes Federation (IDF) Atlas Ninth Edition 2019 provides the latest figures, information and projections on diabetes worldwide. The prevalence worldwide is approximately 463 million adults (20 - 79 years) living with diabetes; by 2045 this will rise to 700 million. Africa has a prevalence burden of more than 19 million people; by 2045 it will be around 47 million. Nigeria has adult total cases of diabetes mellitus of 2,743,800. Furthermore, it revealed that diabetes caused 4.2 million deaths, gulfed at least USD 760 billion dollars in health expenditure in $2019-10 \%$ of total spending on adults.

Carbon monoxide (CO) is a poisonous, colourless, tasteless, odourless and non-irritant gas produced by incomplete combustion of organic materials [6]. It has 200 to 300 times more affinity for haemoglobin $(\mathrm{Hb})$ than oxygen $\left(\mathrm{O}_{2}\right)$, forming carboxyhaemoglobin which is quite stable [6]. This renders haemoglobin incapable of carrying oxygen resulting in tissue hypoxia.

Carbon monoxide poisoning is the inhalation of large quantity of $\mathrm{CO}$ that is harmful to the body. Inhalation of $\mathrm{CO}$ above the threshold concentration could result in morbidity or mortality based on the health status and age of the victim. The pathophysiology of CO poisoning is mainly anchored on the mechanism of hypoxia and the most impacted organs are the brain and heart [7]. Others less impacted are lungs, pancreas, liver and spleen [7]. Symptoms of CO poisoning may include headache, sweating, dizziness, dim vision, tremor and loss of consciousness [8].

Diabetes mellitus is a chronic disease that develops over time. The exact causative agent is not definitive. It is believed to be influenced by hereditary, environment, nutrition and lifestyle [9]. The role of environment has been identified as one of the major causes of diabetes mellitus [10]. Toxic gases such as carbon monoxide are found commonly in the environment, especially amongst nations with poor power supply and infrastructures. Nations with poor power supply rely heavily on generating set for power generation. Generating set is one of the major emitters of CO in Sub-Saharan Africa [11]. Inhalation of carbon monoxide above its threshold consistently over time has been shown to distort biochemical and haematological parameters [11] [12] [13] [14] [15]

A study showed that patients with carbon monoxide poisoning (COP) had a higher risk for DM than non-COP patients [16]. Similarly, elevated concentra- 
tion of exhaled $\mathrm{CO}$ was observed in diabetes reflecting heme oxygenase (HO)-1 induction and oxidative stress [17]. The previous studies did not put into cognizance the direct measurement of serum and vitreous glucose and ancillary biochemical parameters upon exposure to consistent $\mathrm{CO}$. Hence, this study is designed to evaluate the concentrations of serum and vitreous biochemical parameters that are essential in the diagnosis and management of diabetes mellitus. Alterations of these parameters could support the alternative hypothesis that $\mathrm{CO}$ has a palpable effect of instigating diabetes mellitus. This study is therefore deliberately conducted to interrogate the relationship between $\mathrm{CO}$ and diabetes mellitus using an animal model.

\section{Materials and Methods}

\subsection{Study Area}

The animal intoxication and sample extraction were performed at the animal house of the Faculty of Agricultural Sciences, Niger Delta University, Bayelsa State, Nigeria. Similarly, the biochemical analysis was carried in the Chemical Pathology Laboratory of the Niger Delta University Teaching Hospital, Okolobiri, Bayelsa State, Nigeria.

\subsection{Ethics Statement}

The animals used for the study were treated humanely and according to the dictates of the Animal (Scientific Procedures) Act 1986. The ethical approval was granted by the Bayelsa State Ministry of Health, Bayelsa State, Nigeria.

\subsection{Animals, Study Design and Treatments}

Age-mated New Zealand white male albino rabbits obtained from Plateau State were housed for two weeks in ventilated cages prior for use and were kept under standard conditions with ad libitum access to sterile water and fed a soy-free breeding diet bought in Swali market, Yenagoa, Bayelsa State. Housing conditions were carefully controlled (lights on at $07: 00$, off at 19:00, temperature $19^{\circ} \mathrm{C}$ - $21^{\circ} \mathrm{C}$, humidity $45 \%$ - 65\%).

Rabbits showing signs or symptoms of illness prior to exposures were excluded from the study. A total of 20 rabbits constituted the sample size as validated using Mead's resource equation [18].

After two weeks of acclimatization, the rabbits were randomly allocated into four groups. The first group was designated controls that were exposed to air only $(\mathrm{n}=5)$. The remaining three groups of rabbits were exposed daily whole-body to $\mathrm{CO}$ for $30 \mathrm{~min}$ for 10, 20, or 30 days ( $\mathrm{n}=5$ /group). The source of the CO was a portal Sumac generating set. All CO concentrations were constantly monitored using a Carbon Monoxide Meter Gasman-CO (PCE Instrument, UK). Exposure concentrations were never greater than $200 \mathrm{ppm}$ in the chamber. This level was selected based on earlier studies of Goldstein [19] and Struttmann et al. [20], wherein $200 \mathrm{ppm}$ was found to reflect CO concentration 
that will not lead to immediate mortality and morbidity. At $30^{\text {th }}$ minutes after the final exposure, CO-treated rabbits and their aged-matched and weight-matched controls were euthanized mechanically. Bio-samples (i.e., vitreous humor and blood) were then collected for analyses (see below).

\subsection{Sample Collection}

Vitreous humor samples were collected by the method of Coe [21], whereas blood samples were collected from the heart using the method of Ness [22]. Both samples were collected into plain containers. The samples were centrifuged and supernatant separated into other plain containers for immediate laboratory analysis.

\subsection{Laboratory Analysis}

Serum and vitreous glucose were analyzed using glucose oxidase method. Lipid profile, electrolytes, proteins, and renal function markers were measured using methods approved by the World Health Organization (WHO).

\subsection{Statistics}

Values were expressed as mean \pm SEM. Comparison of treatment effects used one-way ANOVA followed by the Bonferroni post hoc test when multiple treatment groups were compared. Pearson correlation was also used to validate relationships between glucose and other essential parameters in the diagnosis of diabetes mellitus. Statistical Package for Social Sciences program v.18-21 (SPSS Inc., Chicago, IL) was employed as the statistical software package.

\section{Result}

Table 1 indicated a significant increase in vitreous glucose, creatinine and urea observed across the studied groups, while concentrations of vitreous total cholesterol, triglyceride, total protein, globulins, sodium, potassium and $\mathrm{pH}$ decreased significantly. Table 2 shows a significant increase in concentrations of serum glucose, triglyceride, creatinine and, on the contrary, serum cholesterol, total proteins, globulins, potassium, and $\mathrm{pH}$ activity decreased. Table 3 and Table 4 show a correlational association between glucose and other associated parameters in the vitreous humor and serum respectively. Vitreous glucose/pH showed a strong significant negative correlation $(r=-0.505, \mathrm{p}=0.046)$, whereas vitreous glucose/creatinine and glucose/urea showed a strong significant positive correlation $(\mathrm{r}=0.604, \mathrm{p}=0.013$; and $\mathrm{r}=0.57, \mathrm{p}=0.019)$. Vitreous glucose/potassium and glucose/globulin showed a weak negative correlation $(\mathrm{r}=-0.550, \mathrm{p}=0.027$; and $\mathrm{r}=-0.231, \mathrm{p}=0.013$ ) respectively. Serum glucose/potassium, glucose $/ \mathrm{pH}$, glucose/cholesterol, glucose/total protein and glucose/globulins showed strong significant negative correlations $(\mathrm{r}=-0.583, \mathrm{p}=0.018 ; \mathrm{r}=-0.728, \mathrm{p}=0.01 ; \mathrm{r}=$ $-0.706, \mathrm{p}=0.02 ; \mathrm{r}=-0.508, \mathrm{p}=0.044$ and $\mathrm{r}=-0.591, \mathrm{p}=0.016$ ) respectively in Table 4. 
Table 1. A multiple comparison of vitreous diabetes mellitus indicators on the basis of duration of chronic CO intoxication.

\begin{tabular}{|c|c|c|c|c|c|c|}
\hline \multirow{2}{*}{ Parameters } & \multirow{2}{*}{ Control } & \multicolumn{5}{|c|}{ Duration of CO Exposure } \\
\hline & & Day 10 & Day 20 & Day 30 & f-value & p-value \\
\hline Glucose $(\mathrm{mmol} / \mathrm{L})$ & $5.20 \pm 0.29$ & $4.38 \pm 1.12$ & $5.48 \pm 2.12$ & $7.38 \pm 0.85^{a b}$ & 3.92 & 0.04 \\
\hline $\mathrm{TC}(\mathrm{mmol} / \mathrm{L})$ & $1.44 \pm 0.05$ & $0.85 \pm 0.13^{a}$ & $0.67 \pm 0.17^{a}$ & $0.55 \pm 0.13^{a b}$ & 38.33 & 0.00 \\
\hline $\mathrm{TG}(\mathrm{mmol} / \mathrm{L})$ & $0.76 \pm 0.06$ & $0.23 \pm 0.04^{a}$ & $0.19 \pm 0.03^{a}$ & $0.16 \pm 0.05^{a b}$ & 171.04 & 0.00 \\
\hline $\mathrm{TP}(\mathrm{g} / \mathrm{L})$ & $4.32 \pm 2.51$ & $2.83 \pm 1.12$ & $2.34 \pm 1.30^{a}$ & $1.80 \pm 0.41^{a}$ & 3.05 & 0.07 \\
\hline $\mathrm{ALB}(\mathrm{g} / \mathrm{L})$ & $1.01 \pm 0.80$ & $1.33 \pm 0.51$ & $0.62 \pm 0.51$ & $0.83 \pm 0.52$ & 0.93 & 0.46 \\
\hline GLO $(g / L)$ & $3.51 \pm 2.42$ & $1.60 \pm 0.61^{a}$ & $1.72 \pm 0.93^{a}$ & $1.11 \pm 0.71^{a}$ & 5.20 & 0.02 \\
\hline Sodium mmol/1 & $140.00 \pm 3.74$ & $140.95 \pm 12.38$ & $132.35 \pm 4.86$ & $131.23 \pm 3.09$ & 2.04 & 0.16 \\
\hline Potassium $\mu \mathrm{mol} / 1$ & $6.15 \pm 0.56$ & $4.66 \pm 0.37^{a}$ & $4.97 \pm 0.70^{a}$ & $4.24 \pm 0.41^{a}$ & 9.69 & 0.00 \\
\hline Chloride $\mu \mathrm{mol} / 1$ & $104.75 \pm 4.03$ & $105.00 \pm 3.92$ & $99.60 \pm 9.52$ & $103.65 \pm 4.82$ & 0.69 & 0.58 \\
\hline $\mathrm{pH}$ & $7.86 \pm 0.05$ & $7.59 \pm 0.02$ & $7.77 \pm 0.07^{a}$ & $7.23 \pm 0.05^{a}$ & 2.75 & 0.09 \\
\hline Creatinine $(\mu \mathrm{mol} / \mathrm{L})$ & $41.75 \pm 9.07$ & $48.75 \pm 4.86$ & $62.25 \pm 4.57^{a b}$ & $80.50 \pm 8.23^{a b c}$ & 23.96 & 0.00 \\
\hline Urea (mmol/L) & $3.93 \pm 0.22$ & $4.05 \pm 0.51$ & $4.43 \pm 0.51$ & $6.25 \pm 0.60^{a b c}$ & 020.16 & 0.00 \\
\hline
\end{tabular}

Legend: $\mathrm{TC}=$ Total Cholesterol; $\mathrm{TG}=$ Triglyceride; $\mathrm{TP}=$ Total Protein; ALB $=$ Albumin; GLO = Globulin; Symbols $-a: \mathrm{p}<0.05$ vs control, $b$ : $\mathrm{p}<0.05$ vs Day 10, $c$ : $<0.05$ vs Day 20; Data are expressed as mean \pm SD; Significant at 0.05 Confidence ( $<<0.05$ ); Concentration of acute CO intoxication $=\leq 200 \mathrm{pm}$.

Table 2. A multiple comparison of serum diabetes mellitus indicators on the basis of duration of chronic CO intoxication.

\begin{tabular}{|c|c|c|c|c|c|c|}
\hline \multirow{2}{*}{ Parameters } & \multirow{2}{*}{ Control } & \multicolumn{5}{|c|}{ Duration of CO Exposure } \\
\hline & & Day 10 & Day 20 & Day 30 & f-value & p-value \\
\hline Glucose (mmol/L) & $4.35 \pm 1.00$ & $5.07 \pm 2.21$ & $5.65 \pm 0.34$ & $10.03 \pm 0.73^{a b c}$ & 16.10 & 0.00 \\
\hline $\mathrm{TC}(\mathrm{mmol} / \mathrm{L})$ & $3.28 \pm 0.20$ & $3.10 \pm 0.29$ & $2.03 \pm 0.25^{a b}$ & $1.89 \pm 0.17^{a b}$ & 37.89 & 0.00 \\
\hline $\mathrm{TG}(\mathrm{mmol} / \mathrm{L})$ & $1.12 \pm 0.09$ & $1.62 \pm 0.23^{a}$ & $1.54 \pm 0.03^{a}$ & $1.53 \pm 0.31^{a}$ & 3.05 & 0.07 \\
\hline $\mathrm{TP}(\mathrm{g} / \mathrm{L})$ & $47.75 \pm 6.24$ & $36.75 \pm 4.03^{a}$ & $33.50 \pm 3.11^{a}$ & $33.50 \pm 3.70^{a}$ & 8.021 & 0.003 \\
\hline $\operatorname{ALB}(g / L)$ & $30.25 \pm 2.36$ & $28.25 \pm 4.92$ & $26.75 \pm 3.86$ & $29.25 \pm 2.99$ & 0.665 & 0.590 \\
\hline GLO $(g / L)$ & $16.50 \pm 6.56$ & $8.50 \pm 1.73^{a}$ & $8.25 \pm 4.99^{a}$ & $4.25 \pm 0.96^{a}$ & 5.870 & 0.010 \\
\hline Sodium mmol/1 & $136.75 \pm 3.40$ & $145.50 \pm 8.78^{a}$ & $133.50 \pm 4.21^{b}$ & $146.75 \pm 2.02^{a c}$ & 1.48 & 0.27 \\
\hline Potassium $\mu \mathrm{mol} / 1$ & $5.05 \pm 0.84$ & $6.53 \pm 2.48$ & $5.46 \pm 0.53$ & $4.64 \pm 0.11$ & 6.13 & 0.01 \\
\hline Chloride $\mu \mathrm{mol} / 1$ & $97.00 \pm 4.69$ & $95.98 \pm 3.73$ & $89.55 \pm 7.03$ & $90.68 \pm 5.97$ & 1.84 & 0.19 \\
\hline $\mathrm{pH}$ & $7.45 \pm 0.04$ & $7.65 \pm 0.05^{a}$ & $7.55 \pm 0.05^{a b}$ & $7.23 \pm 0.05^{a b c}$ & 60.27 & 0.00 \\
\hline Creatinine $(\mu \mathrm{mol} / \mathrm{L})$ & $68.02 \pm 10.01$ & $72.32 \pm 9.01$ & $74.22 \pm 12.04$ & $90.01 \pm 13.22^{a}$ & 0.52 & 0.48 \\
\hline Urea (mmol/L) & $4.02 \pm 1.73$ & $4.80 \pm 0.91$ & $5.00 \pm 1.22$ & $5.80 \pm 0.71$ & 0.72 & 0.56 \\
\hline
\end{tabular}

Legend: $\mathrm{TC}=$ Total Cholesterol; $\mathrm{TG}=$ Triglyceride; $\mathrm{TP}=$ Total Protein; ALB = Albumin; GLO = Globulin; Symbols $-a: \mathrm{p}<0.05$ vs control, $b$ : $\mathrm{p}<0.05$ vs Day 10, $c$ : $\mathrm{p}<0.05$ vs Day 20; Data are expressed as mean $\pm \mathrm{SD}$; Significant at 0.05 Confidence ( $\mathrm{p}<0.05$ ); Concentration of acute CO intoxication $=\leq 200 \mathrm{pm}$. 
Table 3. Relationship between vitreous glucose concentration and ancillary parameters in diabetes mellitus investigations.

\begin{tabular}{ccc}
\hline Bivariate Parameters & Pearson Coefficient $(\mathrm{r})$ & p-valve \\
\hline Glucose/Sodium & -0.375 & 0.156 \\
Glucose/Potassium & -0.550 & $0.027^{\star}$ \\
Glucose/Chloride & -0.078 & 0.775 \\
Glucose/pH & -0.505 & $0.046^{*}$ \\
Glucose/Cholesterol & -0.393 & 0.132 \\
Glucose/Triacylglycerol & -0.227 & 0.398 \\
Glucose/Total Protein & -0.154 & 0.569 \\
Glucose/Albumin & 0.224 & 0.413 \\
Glucose/Globulins & -0.231 & $0.013^{\star}$ \\
Glucose/Creatinine & 0.604 & $0.013^{\star}$ \\
Glucose/Urea & 0.578 & $0.019^{\star}$ \\
\hline
\end{tabular}

${ }^{\star}$ Correlation is significant @ $0.05 ;{ }^{* *}$ Correlation is significant @ 0.01 .

Table 4. Relationship between serum glucose concentration and ancillary parameters in diabetes mellitus investigations.

\begin{tabular}{ccc}
\hline Bivariate Parameters & Pearson Coefficient $(\mathrm{r})$ & p-valve \\
\hline Glucose/Sodium & 0.469 & 0.067 \\
Glucose/Potassium & -0.583 & $0.018^{*}$ \\
Glucose/Chloride & 0.414 & 0.111 \\
Glucose/pH & -0.728 & $0.01^{*}$ \\
Glucose/Cholesterol & -0.706 & $0.02^{*}$ \\
Glucose/Triacylglycerol & 0.196 & 0.468 \\
Glucose/Total Protein & -0.508 & $0.044^{*}$ \\
Glucose/Albumin & -0.170 & 0.950 \\
Glucose/Globulins & -0.591 & $0.016^{*}$ \\
Glucose/Creatinine & -0.106 & 0.695 \\
Glucose/Urea & 0.250 & 0.695
\end{tabular}

${ }^{\star}$ Correlation is significant @ 0.05 ; ${ }^{* *}$ Correlation is significant @ 0.01 .

\section{Discussion}

The study discovered a significant alteration in vitreous and serum concentrations of some of the studied biochemical parameters in the experimental groups intoxicated with moderate concentration of CO (Table 1 \& Table 2). Also, a handful of correlations either positive or negative were also observed between glucose and some ancillary parameters used in the diagnosis and management of diabetes mellitus (Table $3 \&$ Table 4). These findings form the nutshell of this study as X-rayed below. 
This study observed a significant increase in vitreous and serum glucose concentration in the experimental groups intoxicated with moderate concentration of $\mathrm{CO}$ (Table $1 \&$ Table 2). Carbon monoxide perpetrates its ferocity through denial of the body of adequate oxygen supply or hypoxia [7]. In addition to hypoxia, carbon monoxide poisoning may induce immunological and inflammatory reactions in all organs in the human body by producing reactive oxygen species, which are longer lasting and independent of hypoxia [23] [24]. These cumulatively could be the basis of the hyperglycaemia observed in this study. The palpable effect of hypoxia in provoking diabetes mellitus or its complications has been shown by couple of researchers [25] [26]. On the contrary, a review article conducted by Veronica et al. [27] suggested that two environmental toxins, arsenic and dioxin (dibenzo-p-dioxins), may have some relationship to an increased risk for diabetes. Carbon monoxide was not included by the researchers as a risk factor of diabetes mellitus.

A serial significant decrease in concentrations of vitreous and serum total protein and globulin in $\mathrm{CO}$ intoxicated groups was observed when compared with the controls (Table $1 \&$ Table 2). The decrease in vitreous or serum total protein could have been orchestrated by the fall in vitreous or serum globulin. This is due to the non-significant concentration of albumin across the experimental groups. Globulin is an immune protein used as defense by the body against foreign or toxic agent invasion. A fall in total protein and globulin has been shown to be an attribute of immune suppression or depression [28]. A depressed immune system is an opening of floodgate to a lot of diseases. Hence, the depressed immune system could be one of the scientific bases of the provocation of diabetes mellitus. This is further corroborated by the positive correlations between serum glucose and globulin (Table 4), and serum glucose and serum total protein (Table 4). Decreased cellular response and cellular innate immunity has been implicated in diabetes mellitus [29] which concurred with this study. Furthermore Weaver [23] and Hampson et al. [24] also posited the effect of $\mathrm{CO}$ in compromising the immunological status of the body which is in accordance with the posture of this study.

However, this study revealed a significant decrease in concentration of vitreous and serum potassium in the CO intoxicated groups (Table $1 \&$ Table 2). Potassium is the main positively charged electrolyte in the intracellular fluid (ICF), which determines the amount of water inside the cells. Potassium helps the body regulate fluid, send nerve signals and regulate muscle contractions [30]. It is believed that potassium causes the release of insulin from the beta cells of the pancreas [31]. Low concentrations of potassium could be inimical to the efficiency of the pancreas in adequately secreting insulin. A review article emphatically stated that low concentration of potassium can increase the chance of developing diabetes [31]. Hence, the finding on the decrease in potassium concentration further validates the potential risk of diabetes mellitus resulting from $\mathrm{CO}$ intoxication. Carbon monoxide could have an inhibitory or alterative effect on potassium concentration which also forms strings of actions cascading to the 
manifestation of diabetes mellitus.

Vitreous and serum sodium concentration exhibited a significant decrease as the duration of $\mathrm{CO}$ intoxication increases (Table $1 \&$ Table 2). Also, a positive correlation was established between serum sodium and serum glucose (Table 4). The result of this study is in consonance with the rule of thumb in clinical medicine; which advanced that serum sodium concentration decreases by $1.6 \mathrm{mEq} / \mathrm{l}$ for every $100 \mathrm{mg} / \mathrm{dl}$ increase in glucose concentration due to water shifts from the intracellular to the extracellular compartment [32]. An experimental study in healthy subjects found significantly greater decreases in sodium concentration than expected when using the standard correction factor, especially when glucose concentrations were above $400 \mathrm{mg} / \mathrm{dl}$ [33]. Serum chloride also exhibited a decrease in concentration. A decrease concentration of serum chloride is a known risk factor of potential diabetes mellitus. Decreased chloride concentration is related to diabetes mellitus, or a family history of diabetes mellitus [34]. A study on anion gap showed a distorted chloride in diabetes [9].

Vitreous and serum $\mathrm{pH}$ value showed a significant decrease in activity (Table $1 \&$ Table 2). The decrease is scaled towards acidity which is a major attribute of ketoacidosis observed commonly in diabetes mellitus. The finding of this study is in agreement with the stance of Yukimura et al. [35], which established that low $\mathrm{pH}$ is significantly associated with abnormal glucose tolerance. Therefore, measuring $\mathrm{pH}$ might prove useful for identifying patients at high risk for diabetes. Agoro et al. [9] also posited that glucose impairment has the preponderances of eliciting acidotic condition in the body.

Vitreous and serum total cholesterol concentration decreased significantly upon progressive exposure to moderate $\mathrm{CO}$ concentration (Table $1 \&$ Table 2). Similarly, vitreous triglyceride significantly decreased in the vitreous, whereas increased in the serum. Literature has shown that diabetes tends to lower "good" cholesterol concentrations and raise triglyceride and "bad" cholesterol concentrations, which increases the risk for heart disease and stroke. This common condition is called diabetic dyslipidemia [36]. Triglyceride is potentially useful for predicting T2DM in clinical practice. It is a potential mediator of association between BMI and T2DM development [37]. Authors such as Zhang et al. [38] and Lee et al. [39] supported the predictive usefulness of triglyceride. However, Sargsyan and Herman [40] posited that the increase in triglyceride in diabetes mellitus is due to dysregulation of hepatic carbohydrate sensing systems. On the contrary, Beshara et al. [41] showed that sustained increments in serum triglyceride concentration, even within the accepted normal range, are an independent risk factor for diabetes mellitus and impaired fasting glucose in normoglycemic participants.

The significant increase in vitreous and serum creatinine and urea concentrations are an indication of renal dysfunction (Table $1 \&$ Table 2). Furthermore the correlation between vitreous creatinine and urea concentrations and that of glucose concentration is a further proof to the relationship between renal func- 
tion markers and glucose (Table 3). The source of the increase in concentrations of the renal function markers is questionable as both elevation of glucose or the direct toxicity of $\mathrm{CO}$ could initiate the pathophysiology of renal dysfunction. There is a relationship which exists between diabetes mellitus and raised creatinine concentration [42]. Usually, this situation arises when DM has been there for a long time and not controlled and such a situation is referred to as diabetic nephropathy. The reason adduced rule out the possibility of hyperglycaemia causing diabetes mellitus. The finding of this study contradicts the stance of Hjelmesæth et al. [43] which bared that a low serum creatinine concentration is associated with type 2 diabetes, rather than the increase observed in this study. Hence, it could be deduced that the leap in the renal function biomarkers could have emanated from CO intoxication and not the effect of hyperglyceamia.

The major limitation noted in the study is the use of animal model. An advocacy for the use human is apt. Also, more biochemical parameters should be incorporated into the study to increase the scope. Paucity of funds was the major constraint in increasing the scope of the study.

\section{Funding}

No funding was gotten from any source or funding organizations. All financial implications were contributions made by the three authors.

\section{Acknowledgements}

Special appreciation to the staff of Eni-yimini Laboratory (EL) LTD for the sample collection and biochemical analysis.

\section{Conflicts of Interest}

Potential conflicts of interest do not exist.

\section{References}

[1] WHO (World Health Organization) (2013) Diabetes Fact Sheet $N^{\circ} 312$. World Health Organization, Geneva.

[2] American Diabetes Association (2009) Diagnosis and Classification of Diabetes Mellitus. Diabetes Care, 32, 62-67. https://doi.org/10.2337/dc09-S062

[3] WHO (World Health Organization) (2014) About Diabetes. World Health Organization, Geneva.

[4] World Health Organization (2006) Definition and Diagnosis of Diabetes Mellitus and Intermediate Hyperglycemia: Report of a WHO/IDF Consultation. World Health Organization, Geneva, 21.

[5] IDF Diabetes Atlas Group (2015) Update of Mortality Attributable to Diabetes for the IDF Diabetes Atlas: Estimates for the Year 2013. Diabetes Research and Clinical Practice, 109, 461-465. https://doi.org/10.1016/j.diabres.2015.05.037

[6] Rao, N.K. (2006) Cardiac Poisons. In: Rao, N.K. (Author), Textbook of Forensic Medicine and Toxicology, Jaypee Brothers, New Delhi, 425-432.

[7] Prockop, L.D. and Chichkova, R.I. (2007) Carbon Monoxide Intoxication: An Up- 
dated Review. Journal of the Neurological Sciences, 262, 122-130. https://doi.org/10.1016/j.jns.2007.06.037

[8] Anderson, J., Menkedick, J.R. and Wooton, M.A. (2005) Healthy Homes Issues: Carbon Monoxide. Vision 3, US Department of Housing and Urban Development, Washington DC, 1-35.

[9] Agoro, E.S., Wankasi, M.M. and Illeimokum, O. (2015) Relationship between Serum Anion Gap and Diabetes Mellitus. Journal of Diabetes Mellitus, 5, 199-205. https://doi.org/10.4236/jdm.2015.54024

[10] Kristina, A.T., Jerrold, J.H., John, R.B. and Michael, A.G. (2012) Role of Environmental Chemicals in Diabetes and Obesity: A National Toxicology Program Workshop Review. Environmental Health Perspectives, 120, 779-789. https://doi.org/10.1289/ehp.1104597

[11] Agoro, E.S. and Wankasi, M.M. (2018) The Effects of Chronic Carbon Monoxide Intoxication on Some Liver Biochemical Parameters in Rabbits. Journal of Indian Society of Toxicology, 14, 12-16.

[12] Agoro, E.S., Ombor, J.A., Alabrah, P.W. and Tommy, E.O. (2019) The Chronic Influence of Carbon Monoxide Intoxication on Lipid Peroxidation. Journal of Environmental Research, 3, 1-6.

[13] Agoro, E.S., Wankasi, M.M. and Ombor, O.J. (2019) Biochemical Patterns of Cardio-Renal in Serum and Vitreous Humor of Rabbits after Chronic CO Exposure. Annals of Environmental Science and Toxicology, 3, 1-6. https://doi.org/10.17352/aest.000017

[14] Agoro, E.S., Wankasi M.M. and Zebedee, U.L. (2019) The Effects of Chronic Carbon Monoxide Intoxication on Some Haematological Parameters and Films in Rabbits. Advanced Journal of Toxicology, 3, 1-5.

[15] Agoro, E.S., Akubugwo, E.I., Chinyere, G.C., Alabrah, P.W. and Ombor, J.A. (2018) The Cumulative Effects of Chronic Carbon Monoxide Inhalation on Serum and Vitreous Protein and Lipid Panels. American Journal of Research Communication, 6, 20-32.

[16] Huang, C., Ho, C., Chen, Y., Lin, H., Hsu, C., Wang, J., Su, S. and Guo, H. (2017) Increased Risk for Diabetes Mellitus in Patients with Carbon Monoxide Poisoning. Oncotarget, 8, 63680-63690. https://doi.org/10.18632/oncotarget.18887

[17] Paredi, P., Biernacki, W., Invernizzi, G., Kharitonov, S.A. and Barnes, P.J. (1999) Exhaled Carbon Monoxide Levels Elevated in Diabetes and Correlated with Glucose Concentration in Blood: A New Test for Monitoring the Disease? Chest, 116, 1007-1011. https://doi.org/10.1378/chest.116.4.1007

[18] Kirkwood, J. and Robert, H. (2010) The UFAW Handbook on the Care and Management of Laboratory and Other Research Animals. Wiley-Blackwell, Hoboken, 29.

[19] Golden, M. (2008) Carbon Monoxide Poisoning. Journal of Emergency Nursing, 34, 538-542. https://doi.org/10.1016/j.jen.2007.11.014

[20] Struttmann, T., Scheerer, A., Prince, T.S. and Golden, L.A. (1998) Unintentional Carbon Monoxide Poisoning from an Unlikely Source. The Journal of the American Board of Family Practice, 11, 481-484. https://doi.org/10.3122/jabfm.11.6.481

[21] Coe, J.I. (1989) Vitreous Potassium as a Measure of the Postmortem Interval: An Historical Review and Critical Evaluation. Forensic Science International, 42, 201-213. https://doi.org/10.1016/0379-0738(89)90087-X

[22] Ness, R.D. (1999) Clinical Pathology and Sample Collection of Exotic Small Ani- 
mals. The Veterinary Clinics of North America: Exotic Animal Practice, 2, 591-620. https://doi.org/10.1016/S1094-9194(17)30112-3

[23] Weaver, L.K. (2009) Clinical Practice. Carbon Monoxide Poisoning. New England Journal of Medicine, 360, 1217-1225. https://doi.org/10.1056/NEJMcp0808891

[24] Hampson, N.B., Hauff, N.M. and Rudd, R.A. (2009) Increased Long-Term Mortality among Survivors of Acute Carbon Monoxide Poisoning. Critical Care Medicine, 37, 1941-1947. https://doi.org/10.1097/CCM.0b013e3181a0064f

[25] Cameron, N.E., Eaton, S.E., Cotter, M.A. and Tesfaye, S. (2001) Vascular Factors and Metabolic Interactions in the Pathogenesis of Diabetic Neuropathy. Diabetologia, 44, 1973-1988. https://doi.org/10.1007/s001250100001

[26] Li, G., Lu, W.H., Ai, R., Yang, J.H., Chen, F. and Tang, Z.Z. (2014). The Relationship between Serum Hypoxia-Inducible Factor $1 \alpha$ and Coronary Artery Calcification in Asymptomatic Type 2 Diabetic Patients. Cardiovascular Diabetology, 13, Article No. 52. https://doi.org/10.1186/1475-2840-13-52

[27] Veronica, G.P., Rachel, M.M., Barbara, N.L., Barbara, J.H. and Patricia, T.S. (2002). Toxins and Diabetes Mellitus: An Environmental Connection? Diabetes Spectrum, 15, 109-112. https://doi.org/10.2337/diaspect.15.2.109

[28] Agoro, E.S., Ogbotobo, R.I., Ombor, J., Thomas, C., Mac'odo, Y. and Wankasi, M.M. (2012) Relationships between Serum Globulins, Albumin/Globulin Ratio and C-Reactive Proteins in Pregnancy Trimesters. Journal of Medical Laboratory Science, 21, 49-57.

[29] Suzanne, E.G. and Andy, I.M. (1999) Immune Dysfunction in Patients with Diabetes Mellitus (DM). FEMS Immunology \& Medical Microbiology, 26, 259-265. https://doi.org/10.1111/j.1574-695X.1999.tb01397.x

[30] Cheng, C.J., Kuo, E. and Huang, C.L. (2013) Extracellular Potassium Homeostasis: Insights from Hypokalemic Periodic Paralysis. Seminars in Nephrology, 33, 237-247. https://doi.org/10.1016/j.semnephrol.2013.04.004

[31] Diabetes Library (2020) Diabetes and Potassium Levels. https://diabeteslibrary.org/diabetes-and-potassium/\#: :text=Relation\%20of\%20low \%20potassium\%20and\%20ri

[32] Katz, M.A. (1973) Hyperglycemia-Induced Hyponatremia-Calculation of Expected Serum Sodium Depression. New England Journal of Medicine, 289, 843-844. https://doi.org/10.1056/NEJM197310182891607

[33] Hillier, T.A., Abbott, R.D. and Barrett, E.J. (1999) Hyponatremia: Evaluating the Correction Factor for Hyperglycemia. American Journal of Medicine, 106, 399-403. https://doi.org/10.1016/S0002-9343(99)00055-8

[34] Abbas, E.K. and Barry, M.W. (1999) Management of Diabetic Ketoacidosis. American Family Physician, 60, 455-464.

[35] Yukimura, H., Marenao, T., Masato, F., Masayuki, K., Hirofumi, O., Keita, N., Takashi, H., Nagisa, H., Norihito, M. and Tetsuji, M. (2020) Low Urine pH Predicts New Onset of Diabetes Mellitus during a 10-Year Period in Men: BOREAS-DM1 Study. Journal of Diabetes Investigation, 11, 1490-1497. https://doi.org/10.1111/jdi.13284

[36] Buttar, H.S., Li, T. and Ravi, N. (2005) Prevention of Cardiovascular Diseases: Role of Exercise, Dietary Interventions, Obesity and Smoking Cessation. Experimental and Clinical Cardiology, 10, 229-249.

[37] Low, S., Khoo, K.C.J., Irwan, B., Sum, C.F., Subramaniam, T., Lim, S.C. and Wong, T.K.M. (2018) The Role of Triglyceride Glucose Index in Development of Type 2 
Diabetes Mellitus. Diabetes Research and Clinical Practice, 143, 43-49.

https://doi.org/10.1016/j.diabres.2018.06.006

[38] Zhang, M., Wang, B., Liu, Y., Sun, X., Luo, X., Wang, C., Li, L., Zhang, L., Ren, Y., Zhao, Y., Zhou, J., Han, C., Zhao, J. and Hu, D. (2017) Cumulative Increased Risk of Incident Type 2 Diabetes Mellitus with Increasing Triglyceride Glucose Index in Normal-Weight People: The Rural Chinese Cohort Study. Cardiovascular Diabetology, 16, Article No. 30. https://doi.org/10.1186/s12933-017-0514-x

[39] Lee, J.W., Lim, N.K. and Park, H.Y. (2018) The Product of Fasting Plasma Glucose and Triglycerides Improves Risk Prediction of Type 2 Diabetes in Middle-Aged Koreans. BMC Endocrine Disorders, 18, Article No. 33.

https://doi.org/10.1186/s12902-018-0259-x

[40] Sargsyan, A. and Herman, M.A. (2019) Regulation of Glucose Production in the Pathogenesis of Type 2 Diabetes. Current Diabetes Reports, 19, Article No. 77.

https://doi.org/10.1007/s11892-019-1195-5

[41] Beshara, A., Cohen, E., Goldberg, E., Lilos, P., Garty, M. and Krause, I. (2016) Triglyceride Levels and Risk of Type 2 Diabetes Mellitus: A Longitudinal Large Study. Journal of Investigative Medicine, 64, 383-387.

https://doi.org/10.1136/jim-2015-000025

[42] Pyram, R.K., Banerji, M.A. and Loney-Hutchinson, L. (2012) Chronic Kidney Disease and Diabetes. Maturitas, 71, 94-103.

https://doi.org/10.1016/j.maturitas.2011.11.009

[43] Hjelmesæth, J., Røislien, J., Nordstrand, N., et al. (2010) Low Serum Creatinine Is Associated with Type 2 Diabetes in Morbidly Obese Women and Men: A Cross-Sectional Study. BMC Endocrine Disorders, 10, Article No. 6.

https://doi.org/10.1186/1472-6823-10-6 